\title{
MEHKE VEŠČINE V VISOKOŠOLSKEM IZOBRAŽEVANJU
}

Izr. prof. dr. Jaka Vadnjal

GEA College -

Fakulteta za

podjetništvo

Ljubljana

\section{POVZETEK}

Čeprav Evropska komisija v strateških dokumentih daje vse večji poudarek mehkim veščinam, ki naj bi bile ključne za doseganje ciljev bolonjskega procesa, se zdi, da te veščine še niso našle prave poti v visokošolske izobraževalne programe. Razlog je deloma v tradicionalistični usmeritvi visokošolskega prostora, ki daje prednost znanstvenim podlagam študijskih programov pred njihovo aplikativno vrednostjo. Študija se ukvarja z vprašanjem ključnih mehkih veřčin, ki bi jih bilo smiselno povezati s študijskimi programi bodisi kot sestavni del študijskih programov (del modulov ali samostojni modul) bodisi kot zunajštudijskeoblike. Na podlagi raziskave, ki je bila opravljena med kadrovskimi strokovnjaki $v$ šestih državah, je bil prepoznan relativni pomen posameznih mehkih veščin, ki so bile razvrščene v tri ključne skupine: osebne, socialne in metodološko/kontekstualne. V zaključnem delu študije so podani predvideni študijski cilji pri vključevanju mehkih veščin v visokošolske študijske programe.

Ključne besede: mehke veščine, kompetence, visokošolsko izobraževanje, učenje, študijski programi

\section{SOFT SKILLS IN HIGHER EDUCATION - ABSTRACT}

Although in its strategic documents the European Commission emphasizes the importance of soft skills for achieving the key goals of the Bologna process, it seems that soft skills have not found their way into higher education study programs yet. The reason for this is partly in a very traditionalistic stand of the European higher education environment, which gives priority to scientific groundings over practical applicability. This study addresses the question of key soft skills, which should be included in higher education study programs either as independent modules or integrated in the existing modules or else offered as extra curricular activities to students. Based on the empirical research, conducted by human resource experts in six countries, soft skills can be clustered into three groups: personal, social and methodological/contextual. In the concluding part of the paper the expected learning outcomes are defined in order to stimulate inclusion of soft skills into higher education study programs.

Keywords: soft skills, competences, higher education, learning, study programs

UDK: 378

\section{UVOD}

Eno od pomembnih sporočil bolonjskega procesa je med drugim velika potreba po reformi visokega šolstva v Evropi z namenom, da bi univerze postale gibalo sprememb in inovativnosti ter $\mathrm{s}$ tem povezane globalne konkurenčnosti. Ena od predvidenih strateških aktivnosti v zvezi s tem pa je tudi nadgradnja obstoječih visokošolskih programov z znanji in veščinami, po katerih trg dela kaže vse večje potrebe (European Commission: New skills for new jobs). Čeprav se bolonjska reforma izvaja že nekaj let, je na evropskih univerzah še vedno opaziti težave s spremembami: zdi se, da so visokošolski programi še vedno natrpani s tako imenovanim znanstvenim učenjem, ki daje prednost teoretičnim osnovam pred praktičnimi vidiki in uporabno vrednostjo posameznih ved. $\mathrm{V}$ tem zakoreninjenem tradicionalističnem pristopu k podajanju znanja na ravni visokih šol, univerze ali tudi podiplomskih programov je le malo prostora za tako imenovane mehke veščine (ang. softs kills) in komplementarna znanja.

Mehke veščine, ki so komplementarne predmetno specifičnim znanjem in spretnostim posameznega strokovnega in/ali znanstvenega 
področja, so med najbolj pogostimi zahtevami delodajalcev pri iskalcih prve zaposlitve, zato so prav mehke veščine izjemno pomemben dejavnik zaposljivosti študentov oziroma novih diplomantov. Po drugi strani se zdi, da mehkim spretnostim šole in univerze ne namenjajo zadostne pozornosti. Razlog za to je morda v tem, da je izraz mehke veščine veliko slabše in manj poenoteno opredeljen kot bolj udomačen izraz kompetence.

Od vpeljave tristopenjskega izobraževalnega sistema (diploma, magisterij in doktorat) se je pomen mehkih veščin, ki so komplementarne predmetno specifičnemu znanju, povečal. Delodajalci od akademikov pričakujejo, da ne bodo samo strokovnjaki na svojem področju, ampak da bodo imeli izkušnje tudi iz mehkih veščin in da bodo te izkušnje sposobni posredovati študentom (Kohler, 2004; Welbers, 2004). Sposobnost učenja, timsko delo, komunikativnost, ustvarjalnost in druge mehke veščine postajajo jedrni kriterij zaposljivosti (Harvey, 1999; Vukasovic, 2006).

Namen članka je spodbuditi učitelje v visokošolskih in drugi inštitucijah, ki se ukvarjajo z izobraževanjem in usposabljanjem, da začnejo načrtovati in vzpostavljati tako okolje za učenje, ki bo usmerjeno k izobraževalnim ciljem, v katerih bodo upoštevane ustrezne mehke spretnosti, kakršne diplomanti potrebujejo $\mathrm{v}$ kombinaciji s posameznimi vrstami znanja. V članku se ne sprašujemo, kako je te spretnosti mogoče poučevati, ampak identificiramo tri ključna vprašanja, ki bi morala voditi učitelja pri poskusu doseganja prej opisanega cilja. Ta vprašanja so: (1) Katere so tiste mehke veščine, ki jih želim(o) prenesti na študente?, (2) Kako se študenti lahko naučijo neke mehke spretnosti?, (3) Kako naj za študente razvijemo izkušnjo učenja, da bodo učinkovito razvili želeno mehko spretnost?
Ta vprašanja zahtevajo jasno opredelitev ciljev učenja in izobraževanja, brez katere ni mogoče izbrati metod poučevanja in narediti analize njihovih učinkov (Ko, 2010). V raziskavi je bilo prepoznanih 22 mehkih spretnosti, kot jih vidijo kadrovski menedžerji v podjetjih in strokovnjaki, ki se s tem področjem tako ali drugače ukvarjajo na univerzah, raziskovalnih inštitutih in sorodnih organizacijah.

\section{DEFINICIJE KLJUČNIH KONCEPTOV}

$\mathrm{O}$ čem pravzaprav govorimo $\mathrm{v}$ razpravi o mehkih veščinah? Izraz je povezan z mnogimi pomeni in njegovo razumevanje je zelo različno. $\mathrm{V}$ literaturi najdemo veliko opisov mehkih veščin. Glede na to, da je pojem med različnimi narodi in v različnih kulturnih okoljih zelo različno razumljen, je toliko bolj očitno, da je zahteva po njegovi jasni opredelitvi še bolj upravičena.

Mehke spretnosti tako opredelimo kot dinamično kombinacijo kognitivnih in metakognitivnih spretnosti, medosebnostnih, intelektualnih in praktičnih spretnosti ter etičnih vrednot. Mehke spretnosti pomagajo ljudem, da se prilagajajo trenutnim okoliščinam in se obnašajo pozitivno, tako da so se sposobni učinkovito spopadati z vedno novimi izzivi profesionalnega in vsakodnevnega življenja (Duncan in Dunifon, 1998). Metode poučevanja razumemo kot sistem različnih dejavnosti, ki jih skupaj izvajajo tisti, ki se učijo, in tisti, ki poučujejo in so osredotočeni na vnaprej določene cilje učnega procesa. Primeri poučevanja so tako: predavanje, reševanje problemov, razmišljanje v parih in podobno. Metode poučevanja so običajno in značilno generični opisi aktivnosti ne glede na specifičen kontekst njihove uporabe. Metode ocenjevanja razumemo kot opis celotne metodologije ocenjevanja, ki razkriva vse dimenzije, ki jih vsebuje končna ocena (Barrie, 2007). Cilji učenja pa jasno 
opredeljujejo, kaj mora učenec na koncu učnega procesa vedeti, znati ali biti sposoben narediti. Prav cilji učenja so ključna dimenzija razprave o mehkih spretnostih in odgovora na vprašanje, ali sploh in v kakšni meri se je mehkih spretnosti mogoče naučiti v sklopu rednih učnih ali študijskih programov (Dunlap, 2005).

\section{PEDAGOŠKI OKVIR MEHKIH VEŠČIN}

Podlage za poučevanje in učenje, ki jih uporabljamo v tem članku, so izpeljane iz treh različnih šol, ki imajo sicer veliko skupnega: (1) konstruktivizma, (2) situacijskega učenja in (3) na človeka osredotočenega učenja (ang. person centered learning). Teoretični fokus konstruktivizma je v ustvarjanju kognitivnih struktur, kot so na primer: mentalni modeli, konceptni zemljevidi oziroma sheme, in reorganizaciji kognitivnih vzorcev skozi interakcijo z okoljem in drugimi ljudmi (Von Glasersfeld, 1997; Schmidt, 1987). Procese ustvarjanja novega znanja poganjajo predvsemposamezniki, zato jih pri posameznikih tudi najprej uporabimo, tako da jih spodbujamo. Učenje je aktivno mentalno delo in ne pasivno sprejemanje poučevanja (Motschnig-Pitrik in Rohlíkova, 2013). V konstruktivistični postavitvi je ključna naloga učitelja, da postane nekakšen trener (ang. coach), ki učencem predvsem pomaga, in sicer tako, da vzpostavi spodbudno okolje za učenje, v katerem lahko posamezniki v okviru skupine dosežejo samostojne vpoglede v neko znanje, ali pa z različnimi metodami poučevanja pripomore $\mathrm{k}$ individualnemu pridobivanju znanja (Von Glasersfeld, 1997). Ker so aktivni procesi učenja osrednji del konstruktivizma, se zdi ta pristop $\mathrm{k}$ poučevanju in učenju $\mathrm{z}$ namenom razvoja mehkih spretnosti najbolj smiseln in logičen. To ugotovitev podpira vrsta študij. Aksal in drugi (2008) s študijo primera pokažejo, kako konstruktivistične metode spodbu- jajo razvoj mehkih spretnosti dodiplomskih študentov informacijske tehnologije. Gruba in Søundergaard (2001) poročata o uspešni uporabi konstruktivističnih metod pri študentih komunikologije. Mothschnig-Pitrik in Holzinger (2002) poudarjata, da je glavni cilj konstruktivizma kompetenca in ne znanje kot $\mathrm{v}$ kognitivizmu ali dosežek kot $\mathrm{v}$ behaviorizmu.

V teoriji situacijskega učenja, kot sta jo postavila Lave in Wenger (2000), je bistvo učenja v skupnem ustvarjanju znanja $v$ procesu socialne interakcije med posamezniki. Teorija situacijskega učenja prestavlja pozornost s posameznikovega mišljenja na povezovanje med mišljenji več ljudi (Yuan in Mehke spretnosti
so dinamična
kombinacija
kognitivnih in
metakognitivnih
spretnosti. McKelvey, 2004).

Pravimo, da je učenje situacijsko vpeto $\mathrm{v}$ aktivnosti, kontekst in kulturo posameznika in skupine (McLellan, 1985). Učenci torej niso izolirani posamezniki, ampak udeleženci skupnosti in skupine ljudi. V skupinsko učenje so vključeni na podlagi medčloveških stikov in interakcij (Wenger, 2006). Zaradi skupnega interesa in vzajemne delitve kompetenc so člani skupnosti povabljeni k skupnim dejavnostim in diskusijam, zagotavljanju pomoči drug drugemu ter izmenjavi informacij in izkušenj. Skupaj razvijejo nabor različnih virov, na primer zgodbe, orodja in načine reševanja različnih problemov, kot različna sredstva za razširjanje skupnih izkušenj. V situacijskem učenju učitelji prevzemajo vlogo izkušenega trenerja ter zagotavljajo orodja in pomoč. Usposobljeni so za to, da prepoznajo in razumejo kompleksne spremenljivke, ki so v dinamiki skupinskega učenja med sabo soodvisne. Skupaj s slušatelji delajo na kompleksnih problemih in se vključujejo v diskusije s študenti (Gee, 2008). 
Zdi se, da je razvoj mehkih spretnosti osredotočen okoli situacijskega učenja. Komunikacija, timsko delo in sposobnost učenja so temelj kolektivnega učenja $\mathrm{v}$ praktično usmerjenih skupnostih. $\mathrm{Z}$ vidika organizacij se od slušateljev pričakuje, da bodo mehke veščine uporabljali v različnih delovnih okoliščinah. Zaradi tega je situacijsko učenje še posebno primerno in popolnoma $\mathrm{v}$ kontekstu razvoja mehkih spretnosti (Shakespeare in drugi, 2007).

Osebnostno osredotočeno učenje temelji na hipotezi o izkušnji zaupanja, da lahko študenti raziskujejo področja, ki jih zanimajo, in imajo pri iskanju rešitev hkrati na voljo pomoč in spodbudo ter podporo mentorja. $\mathrm{V}$ tem procesu ne dosegajo samo višje ravni akademskih kompetenc, ampak si bodo pridobili tudi osebnostne veščine, kot sta fleksibilnost in samozaupanje, ter družbene spretnosti (Mothschnig, 2010).

Rogers (1983) takole opisuje značilnosti pomembnega učenja (ang. significant learning): »Ima kvaliteto osebnega vključevanja - celotna osebnost je s čustvi in kognitivnim vidikom vključena v dogodek učenja oziroma izobraževanja. Tudi kadar impetus ali stimulus prideta od zunaj, pa občutki odkrivanja, doseganja in sestavljanja stvari prihajajo od znotraj. To povzroča razlike pri obnašanju, prikaže različna nagnjenja in morda celo vpliva na osebnost učenca. Učenec ocenjuje sam sebe. Dobro ve, ali izpolnjuje pričakovanja, ali gre proti tistemu, kar želi vedeti, in ali osvetljuje temno področje ignorance, ki jo doživlja. Središče vrednotenja je definitivno na strani tistega, ki se uči. Ključen je pomen. Ko se dogaja tako učenje, je element pomena za učenca vgrajen v celotno izkušnjo.« Posredovanje pri uspešnem učenju je odvisno od posebnih nagnjenj $\mathrm{k}$ učenju ter se skriva $\mathrm{v}$ osebnem odnosu med učiteljem in učencem. Če učenci učitelja vsaj deloma dojemajo kot pristnega, zaupanja vrednega in razumevajočega, so izpolnjeni pogoji za pomembno učenje. Učitelji, ki so osredotočeni na slušatelja kot osebnost, se trudijo vzpostaviti medosebne odnose s slušatelji in tudi znotraj skupine slušateljev. $\mathrm{V}$ takih okoliščinah - pod pogojem, da se $\mathrm{v}$ njih dobro počutijo -, so takšni učitelji običajno neukazovalni (ne dajejo neposrednih navodil), čeprav občasno uporabljajo tudi take metode poučevanja (Rogers, 2005).

Glavni vidik konstruktivizma je, kot kaže, da je znanje $\mathrm{v}$ funkciji organizacije $\mathrm{v}$ kontekstu izkustvenega sveta, in zato je ključna aktivnost prav ustvarjanje novega znanja. Obstaja jasna usmeritev $\mathrm{v}$ prilagajanje, prirejanje in ustvarjanje znanja. V situacijskem učenju, kot kaže, osrednjo vlogo igra prav kolektivno ustvarjanje znanja. Na osebnost osredotočeno učenje pa poudarja prav prilagajanje izkušenj, ki bolje motivira in ustvarja vzdušje za nemoten pretok znanja različnih zvrsti, skritega $\mathrm{v}$ posameznikih, ki ima kakršnokoli relevantnost za posameznika (Motschnig-Pitrik in Rohlíkova, 2013).

V situacijskem učenju je posebna pozornost namenjena kontekstualizaciji vrednot, čustev in razmišljanja v kolektivni, kulturni in zgodovinski obliki lokalizirane, zainteresirane, konstruktivno konfliktne in pomenske aktivnosti (Murphy, 2003).

Vse tri teorije učenja vrednotijo učinke učenja s preverjanjem osebne izkušnje. V konstruktivizmu učeči se iščejo izvedljive rešitve za kompleksne probleme. V situacijskem učenju izboljšujejo svoje znanje in veščine na področju svojega osebnega zanimanja. Pomembnostno učenje nastopi, ko so učeči se kognitivno, socialno in s svojimi občutji vključeni v probleme, ki so zanje osebno pomembni. Ukvarjanje $\mathrm{z}$ avtentičnimi in realnimi problemi 
je torej ključni poudarek vseh treh teorij učenja. Uporaba informacijske in komunikacijske tehnologije je lahko zelo učinkovita za spodbujanje učenja v konstruktivizmu, situacijskem in osebno osredotočenem (ang. person centered) učenju. Komunikacijske platforme, kot so na primer diskusijski forumi ali wikiji, so lahko uporabne za osebno izmenjavo izkušenj in so pogosto integrirane kot orodja $\mathrm{v}$ sistemih učenja oziroma izobraževanja na daljavo (ang. blended-learning) (Bauer in drugi, 2006).

\section{Metodologija}

Rezultate, ki jih prikazujemo v nadaljevanju, smo pridobili v sklopu večletnega projekta MODES, ki ga je financirala Evropska komisija v okviru Programa vseživljenjskega učenja v letih 2009 do 2012. V njem so sodelovale izobraževalne inštitucije $\mathrm{z}$ različnih strokovnih oziroma študijskih področij. Vključene so bile države: Italija (zdravstveno

Tabela 1: Opredelitve mehkih veščin varstvo), Avstrija (tehnične vede), Malta (turistične študije), Velika Britanija (družbene vede), Latvija (poslovne vede), Španija (tehnološke vede), Poljska (splošna univerza) in Slovenija (poslovne vede). Raziskavo smo skupaj izvajali pedagogi in raziskovalci ter strokovnjaki, ki se na posameznih inštitucijah ukvarjamo s študentsko infrastrukturo in obštudijskimi dejavnostmi.

Definicija mehkih veščin za namen te študije je bila postavljena v več korakih. Najprej smo s pregledom literature poskušali postaviti definicije veščin, mehkih veščin in kompetenc $\mathrm{v}$ tematskem kontekstu. Pri tem velja omeniti, da sta Knight in Page (2007) poudarila, da so te kompetence pogosto nedeterminirane, kar pomeni, da je redko možno popolnoma opredeliti, kaj pravzaprav pomeni, da je nekdo na primer »kompetenten $\mathrm{v}$ čustveni inteligenci $\ll$. Veščine in znanje ne bi smeli biti opredeljeni z ozkimi in omejevalnimi izrazi (Yorke in Longden, 2008). Opredelitve mehkih veščin, kot smo slednje razumeli za potrebe

\begin{tabular}{|c|c|c|}
\hline & Mehka veščina & Opis \\
\hline 1 & Komunikativnost & $\begin{array}{l}\text { Sposobnost prenašanja idej, informacij in mnenj, jasno in prepričliivo, ustno in pisno, skupaj } \\
\text { s sposobnostjo poslušanja in odprtostjo za predloge drugih. }\end{array}$ \\
\hline 2 & $\begin{array}{l}\text { Usmerjenost k strankam/upo- } \\
\text { rabnikom }\end{array}$ & $\begin{array}{l}\text { Sposobnost učinkovito prepoznati, razumeti in zadovoljiti potrebe obstoječih in bodočih } \\
\text { strank. }\end{array}$ \\
\hline 3 & Timsko delo & $\begin{array}{l}\text { Sposobnost zgraditi vezi pri sodelovanju z drugimi ljudmi. Vključuje delitev virov in prena- } \\
\text { šanje znanja, usklajevanje interesov in dejavno prispevanje k doseganju ciljev organizacije. }\end{array}$ \\
\hline 4 & Sposobnost učenja & $\begin{array}{l}\text { Sposobnost zagotoviti samooceno potreb po znanju (praktičnem in teoretičnem), ukrepati } \\
\text { za pridobitev in implementacijo tega znanja ter hkrati zadržati fleksibilen in odprt odnos do } \\
\text { učenja skozi vse profesionalno življenje. }\end{array}$ \\
\hline 5 & Kreativnost / inovativnost & $\begin{array}{l}\text { Sposobnost prispevati nove ideje za izboljševanje proizvodov in storitev organizacije ter tudi } \\
\text { procesov na delovnem mestu z namenom razvoja organizacije. }\end{array}$ \\
\hline 6 & Sprejemanje odločitev & $\begin{array}{l}\text { Sposobnost hitrega in proaktivnega sprejemanja odločitev. Odločanje zajema zbiranje infor- } \\
\text { macij za izbiro najboljše alternative (s posvetovanjem z najprimernejšimi viri, preverjanjem } \\
\text { in implementiranjem alternative) in vključuje tudi predpostavko tveganja, saj so odločitve } \\
\text { vedno sprejete v razmerah določenega tveganja. }\end{array}$ \\
\hline 7 & Analitične sposobnosti & $\begin{array}{l}\text { Sposobnost oblikovanja zaključkov in napovedi s pridobivanjem informacij iz različnih virov } \\
\text { in ugotavljanjem vzročnih povezav. }\end{array}$ \\
\hline
\end{tabular}




\begin{tabular}{|c|c|c|}
\hline & Mehka veščina & Opis \\
\hline 8 & Menedžerske sposobnosti & $\begin{array}{l}\text { Sposobnost postavljati cilje in prioritete } z \text { izbiro in distribucijo nalog in virov, spremljati izva- } \\
\text { janje in doseganje ciljev ter ukrepati ob odstopanju od osnovnih načrtov. }\end{array}$ \\
\hline 9 & Prilagodliivost spremembam & Sposobnost preusmeriti dejavnosti v skladu z novimi cilji v novih razmerah. \\
\hline 10 & Voditeljstvo (leadership) & $\begin{array}{l}\text { Sposobnost motivirati in voditi druge, da bodo učinkovito prispevali k skupnemu doseganju } \\
\text { ciljev organizacije. }\end{array}$ \\
\hline 11 & $\begin{array}{l}\text { Predanost in identifikacija z } \\
\text { organizacijo }\end{array}$ & $\begin{array}{l}\text { Sposobnost predati se organizaciji in razumeti specifične lastnosti z združevanjem osebnih } \\
\text { značilnosti in profesionalnih odgovornosti z vrednotami, načeli in cilii organizacije. }\end{array}$ \\
\hline 12 & Usmerjenost $\mathrm{k}$ rezultatom & $\begin{array}{l}\text { Sposobnost narediti organizacijske napore dobičkonosne in pri tem stalno imeti v mislih } \\
\text { temeline cilje. Vključuje optimizacijo upravljanja časa, postavljanje prioritet za prihodnje } \\
\text { aktivnosti ter uporabo tehnik in orodij za nïhovo lažje uveljavljanje. }\end{array}$ \\
\hline 13 & Stalne izboljšave & $\begin{array}{l}\text { Sposobnost opravljati aktivnosti ter izpolnjevati dolžnosti in odgovornosti v skladu s stan- } \\
\text { dardi kakovosti in v iskanju stalnega izboljševanja s predlogi prilagoditev in modernizacije } \\
\text { uporabljenih procesov in tehnik. }\end{array}$ \\
\hline 14 & Pogajanja & $\begin{array}{l}\text { Sposobnost jasnega in koherentnega argumentiranja ter odzivanja na različna mnenja za } \\
\text { doseganje kompromisa, ki zadovoljuje vse z namenom doseganja predlaganih ciljev. }\end{array}$ \\
\hline 15 & Profesionalna etika & Sposobnost delovati ob stalnem zavedanju elementov profesionalne etike. \\
\hline 16 & $\begin{array}{l}\text { Odpornost proti stresnim situ- } \\
\text { acijam }\end{array}$ & $\begin{array}{l}\text { Sposobnost pokazati vzdržljivost v zapletenih in stresnih situacijah, v primeru ovir, dodatnih } \\
\text { delovnih obremenitev in načinov dela, z vzdrževanjem enakega standarda kakovosti } \\
\text { opravljenega dela. }\end{array}$ \\
\hline 17 & Samozavedanje & $\begin{array}{l}\text { Sposobnost zavedanja svojih slabosti in prednosti kakor fudi motivacijskih dejavnikov in } \\
\text { vrednot, ki pogojujejo posameznikovo obnašanje. }\end{array}$ \\
\hline 18 & Življenjsko ravnotežje & $\begin{array}{l}\text { Sposobnost učinkovitega upravljanja konfliktov med zasebnim življenjem in službo, med } \\
\text { zasebnimi in organizacijskimi cilji ter med zasebnimi in organizacijskimi vrednotami. }\end{array}$ \\
\hline 19 & Upravljanje konfliktov & $\begin{array}{l}\text { Sposobnost upravljanja konfliktov, kar pomeni stimuliranje, reguliranje in razreševanje kon- } \\
\text { fliktov med različnimi stranmi. }\end{array}$ \\
\hline 20 & Kulturna prilagodliivost & Sposobnost izvajanja menedžerskih in podjetniških procesov v multikulturnih okoljih. \\
\hline 21 & Mreža stikov & $\begin{array}{l}\text { Sposobnost razvijanja, krepitve in vzdrževanja internih in eksternih stikov z namenom dose- } \\
\text { ganja najboljših rezultatov za organizacijo in ohranjanjem njenega imidža. }\end{array}$ \\
\hline 22 & $\begin{array}{l}\text { Veščine raziskovanja in uprav- } \\
\text { ljanja informacii }\end{array}$ & $\begin{array}{l}\text { Sposobnost iskanja informacij v literaturi, razlikovanja med primarnimi in sekundarnimi viri } \\
\text { literature, uporabe različnih informacijskih virov od tradicionalnih do elektronskih, uporabe } \\
\text { različnih raziskovalnih in ocenjevalnih metod. }\end{array}$ \\
\hline
\end{tabular}

Vir: Definicije so povzete po različnih avtoriih s seznama literature.

raziskavMODES, so zbrane $\mathrm{v}$ Tabeli 1 in so bile konsenzualno dogovorjene med vsemi partnerji na projektnem sestanku.

V naslednjem koraku je bil oblikovan anketni vprašalnik, s katerim smo merili pomen posameznih mehkih veščin. Uporabili smo Li- kertovo lestvico, kjer je ocena 1 pomenila, da je mehka veščina popolnoma nepomembna, in ocena 5 , da je izjemno pomembna oziroma ključna. Na anketo so odgovarjali predstavniki delodajalcev. Skupno smo v vzorec vključili 353 ljudi iz vseh držav, iz katerih so prihajali partnerji projekta. Vzorčenje je bilo 
oportunistično, in sicer po načelu, da je vsak partner poskušal pridobiti najmanj 50 ljudi, ki bi odgovorili na vprašalnik, večinoma iz svojih baz kontaktov poslovnih partnerjev. Zaradi načina vzorčenja ne moremo govoriti o statistično značilnem vzorcu, vendar zaradi namena merjenja, ki je bil pripisovanje relativne pomembnosti posameznim mehkim veščinam, lahko vzorčenje ocenimo kot primerno in predpostavimo, da $\mathrm{z}$ vidika statističnih raziskav bolj korektno merjenje ne bi bistveno spremenilo rezultatov oziroma ugotovitev.

$\mathrm{V}$ tretjem koraku smo s pomočjo raziskovalne in strokovne literature opredelili, katere kompetence oziroma učne dosežke naj bi imel posameznik z namenom pridobivanja oziroma izboljšanja posamezne mehke veščine. Metodološko gre pri pričujoči raziskavi za kombinacijo študija literature, ta pa je bila podlaga za empirično raziskavo, iz katere praktično uporabnost razvijamo na podlagi obstoječega znanja in vedenja o posamezni mehki veščini.

\section{REZULTATI}

Rezultati anketiranja predstavnikov delodajalcev iz Avstrije, Italije, Španije, Velike
Britanije, Malte in Slovenije so zbrani v Tabeli 2. Podane so povprečne vrednosti pomena posameznih mehkih veščin, pri čemer je 1 pri anketiranju pomenilo, da gre za popolnoma nepomembno mehko veščino, in 5 , da je veščina izjemno pomembna. $Z$ namenom grupiranja opredeljenih in ocenjenih mehkih veščin je bila izvedena statistična metoda MDS (Multi Dimensional Scaling), s katero smo na podlagi matrike podobnosti parov določili skupine mehkih veščin, ki smo jih poimenovali (1) osebne, (2) socialne in (3) kontekstne/metodološke, kar je v skladu z ugotovitvami predhodnih študij (Chur, 2004).

Iz Tabele 2 je skupaj s sumiranimi vrednostmi razvidno, da so anketiranci največji pomen pripisali socialnim veščinam $(3,70)$, potem kontekstualno/metodološkim $(3,51)$, najmanjšo pa osebnim veščinam $(3,26)$. Zaradi majhnosti vzorcev nismo primerjali stališč med posameznimi državami, kar je omejitev študije, saj je možno, da je pripisovanje pomena posameznim veščinam pogojeno s kulturološkimi razlikami (bolj individualistične družbe $\mathrm{v}$ primerjavi z bolj kolektivističnimi).

Tabela 2: Skupine mehkih veščin

\begin{tabular}{|c|c|c|}
\hline Osebne $(3,26)$ & Socialne $(3,70)$ & Kontekstualne/metodološke $(3,51)$ \\
\hline $\begin{array}{ll}\text { - } & \text { Sposobnost učenja }(3,85) \\
\text { - } & \text { Profesionalna etika }(3,74) \\
\text { - } & \text { Samozavedanje }(3,58) \\
\text { - } & \text { Odpornost proti stresnim situacijam } \\
& (3,34) \\
\text { - } & \text { Predanost in identifikacija z } \\
\text { - } & \text { organizacijo }(3,10) \\
\text { - } & \text { Kulturnarna prilagodljivost }(2,31)\end{array}$ & $\begin{array}{ll}\text { - } & \text { Komunikativnost }(4,48) \\
\text { - } & \text { Usmerienost k strankam/ } \\
\text { - } & \text { Timsko delo }(4,10) \\
\text { - } & \text { Mreža stikov }(3,28) \\
\text { - } & \text { Pogajanja }(3,27) \\
\text { - } & \text { Upravljanje konfliktov }(3,18) \\
\text { - } & \text { Voditelistvo (leadership) }(3,27)\end{array}$ & $\begin{array}{ll}\text { - } & \text { Stalne izboljšave }(3,71) \\
\text { - } & \text { Prilagodliivost spremembam } \\
\text { - } & (3,69) \\
\text { - } & \text { Ansmerienost k rezultatom }(3,70) \\
\text { - } & \text { Sprejemanje odločitev }(3,43) \\
\text { - } & \text { Menedžerske sposobnosti }(3,16) \\
\text { - } & \text { Kreativnost/inovativnost }(3,45)\end{array}$ \\
\hline
\end{tabular}

Vir: lastna raziskava MODES, 2010 
V naslednjem koraku smo se ukvarjali z vprašanjem, kako identificirane mehke veščine vključevati v učni proces, pri čemer smo upoštevali dve možnosti, in sicer: (1) ločene veščine je treba poučevati v specializiranih oblikah (samostojni predmeti, seminarji, delavnice itd.), in (2) integrirane veščine, ki se jih je možno naučiti s pridobivanjem kompetence pri drugih študijskih vsebinah. Delitev veščin na ločene in integrirane je razvidna iz Tabele 3. Delitev smo metodološko izvedli tako, da je vsak od partnerjev v projektu opravil intervjuje s po tremi izobraževalnimi strokovnjaki iz svoje države. Odstopanj posameznikov pri pridobljenih rezultatih praktično ni bilo.

Zadnji del raziskave smo spet opravili po metodi namiznega raziskovanja, in sicer tako, da smo s pregledom raziskovalne literature posameznim mehkim veščinam pripisali predvidene kompetence oziroma učne cilje, ki naj jih posameznik osvoji za obvladovanje posamezne mehke veščine. Povzetek tega dela študije je prikazan v Tabeli 4 , pri čemer je treba poudariti, da so si bili strokovnjaki iz prejšnjega koraka enotni, da je pri analizi želenih učnih dosežkov smiselno izločiti tri kompetence (Tabela 1, pod zaporedno številko: 11, 15 in 17): predanost in identifikacija $\mathrm{z}$ organizacijo, profesionalna etika in samozavedanje, saj je bilo ocenjeno, da so te veščine opredeljene s karakternimi značilnostmi posameznika in njegovim vrednostnim sistemom ter se jih je kot take težko naučiti oziroma priučiti.

\section{ZAKLJUČEK}

Mehke veščine so bile doslej zanemarjeni del visokošolskih študijskih programov, kar izhaja predvsem iz tradicionalistične usmeritve evropskega visokošolskega izobraževanja, ki daje na raziskovanju in teoretičnih podlagah temelječemu znanju večji poudarek in veljavo kot zmožnosti posameznikov, da to znanje praktično uporabijo. Prav praktična uporabljivost rezultatov in dosežkov učenja in izobraževanja pa je eden od ključnih postulatov bolonjskega procesa. $\mathrm{V}$ tem

Tabela 3: Ločene in integrirane veščine

\begin{tabular}{|c|c|}
\hline Ločene veščine & Integrirane veščine \\
\hline $\begin{array}{ll}\text { - } & \text { Kreativnost/inovativnost } \\
\text { - } & \text { Komunikativnost } \\
\text { - } & \text { Timsko delo } \\
\text { - } & \text { Pogajanja } \\
\text { - } & \text { Upravljanje konfliktov } \\
\text { - } & \text { Voditeljstvo (leadership) } \\
\text { - } & \text { Menedžerske sposobnosti } \\
\text { - } & \text { Veščine raziskovanja in upravljana informacij }\end{array}$ & $\begin{array}{ll}\text { - } & \text { Sposobnost učenja } \\
\text { - } & \text { Odpornost proti stresnim situacijam } \\
\text { - } & \text { Življenjsko ravnotežje } \\
\text { - } & \text { Mreža stikov } \\
\text { - } & \text { Kulturna prilagodlijivost } \\
\text { - } & \text { Usmerjenost k strankam/uporabnikom } \\
\text { - } & \text { Stalne izbolišave } \\
\text { - } & \text { Prilagodljivost spremembam } \\
\text { - } & \text { Usmerjenost k rezultatom } \\
\text { - } & \text { Analitične sposobnosti } \\
\text { - } & \text { Sprejemanje odločitev }\end{array}$ \\
\hline
\end{tabular}


Tabela 4: Učni dosežki za posamezne mehke veščine

\begin{tabular}{|c|c|c|}
\hline & Mehka veščina & Učni dosežki \\
\hline 1 & Komunikativnost & $\begin{array}{l}\text { - Transparentna komunikativnost kot rezultat povečane skladnosti in zaupanja. } \\
\text { - } \quad \text { Vaje za aktivno poslušanje. } \\
\text { - Jasno in prepričljivo predstavljanje v javnosti. } \\
\text { - } \quad \text { Opazovanje in upravljanje komunikacijskih vzorcev v skupini. } \\
\text { - } \quad \text { Izrazna in učinkovita komunikacija na štiri oči in on-line. } \\
\text { - Izrazna in učinkovita pisna komunikacija. }\end{array}$ \\
\hline 2 & $\begin{array}{l}\text { Usmerjenost k strankam/upo- } \\
\text { rabnikom }\end{array}$ & $\begin{array}{l}\text { - Ugotoviti področja, na katerih je organizacija osvojila usmerjenost k strankam, in } \\
\text { oceniti, kje in kako se da to še razvijati. } \\
\text { - } \quad \text { Vključevanje strank v postavljanje realističnih ciljev in časovnih okvirov. } \\
\text { - } \quad \text { Postavljanje vprašanj za ugotavljanje potreb, pričakovanj in stopnje zadovoljstva strank } \\
\text { - } \quad \text { ali določitve zavedanja strank, kakšen obseg storitev je na voljo. } \\
\text { - } \quad \text { Odzivanje na stranke s pravo mero nujnosti. }\end{array}$ \\
\hline 3 & Timsko delo & $\begin{array}{l}\text { - Oceniti svojo komunikativnost, sposobnost reševanja konfliktov in sprejemanja odločitev. } \\
\text { - Učinkovita uporaba različnih timskih procesov (brainstorming, strukturna } \\
\text { organiziranost, sestanki). } \\
\text { - Ocena sebe kot člana tima in iskanje možnosti za izboljšanje. } \\
\text { - Učinkovita interakcija in delo z drugimi. }\end{array}$ \\
\hline 4 & Sposobnost učenja & $\begin{array}{l}\text { - Vzpostavljanje ciljev s kriteriji uspeha za razvoj in delo. } \\
\text { - } \quad \text { Presojanje in sprejemanje zaključkov. } \\
\text { - } \quad \text { Povezovanje lastnih in drugih idej z izkušnjami. } \\
\text { - } \quad \text { Pozitiven odgovor na spremembe ter iskanje nasvetov in podpore, ko je potrebno. } \\
\text { - } \quad \text { obvertovanje z izdelavno natančnega urnika študijskih, delovnih, osebnih in družabnih } \\
\text { - Sposobnost razvijanja individualnih učnih strategij z namenom osvajanja novih znanj. } \\
\text { - Ugotavljanje potreb po učenju z namenom zapolnjevanja vrzeli med tem, kar se } \\
\text { naučimo, in tem, kar bi morali znati, da bi tako izboljšali delovno učinkovitost. }\end{array}$ \\
\hline 5 & Kreativnost/inovativnost & $\begin{array}{l}\text { - Uporaba novih metod za opravljanje zahtevanih nalog, iskanje »boljše poti«. } \\
\text { - Uvajanje strategij za upravljanje stalno spreminjajočega se profesionalnega okolja. } \\
\text { - } \quad \text { Izboljšanje sposobnosti za praktičen in kreativen odziv na probleme in priložnosti. } \\
\text { - Vzpostavljanje okvirov in strategij za omogočanje podpornega okolja za kreativnost } \\
\text { in inovativnost, na primer izmenjava idej na forumih, spodbujanje timskih procesov v } \\
\text { vzdušju vzajemnega spoštovanja in podpore. }\end{array}$ \\
\hline 6 & Sprejemanje odločitev & 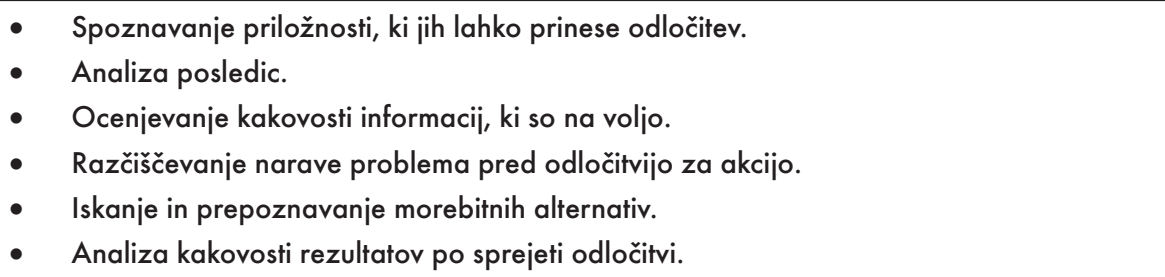 \\
\hline
\end{tabular}




\begin{tabular}{|c|c|c|}
\hline & Mehka veščina & Učni dosežki \\
\hline 7 & Analitične sposobnosti & $\begin{array}{l}\text { - Prepoznavanje in analiza problemov } v \text { težavnih situacijah ter sposobnost napraviti } \\
\text { verodostojno oceno. } \\
\text { - } \quad \text { Iskanje idej in alternativnih rešitev. } \\
\text { - } \quad \text { Sprejemanje utemeljenih zaključkov. } \\
\text { brainstorminga v specifičnih okoliščinah. } \\
\text { - Uporaba za posamezen problem relevantnih teorij. } \\
\text { - } \quad \text { Potrjevanje in nasprotno dokazovanje specifičnih dogodkov in/ali problemov } v \text { širši kontekst. }\end{array}$ \\
\hline 8 & Menedžerske sposobnosti & $\begin{array}{l}\text { - Razvijanje menedžerskih sposobnosti kot del timskega dela. } \\
\text { - } \quad \text { Dokumentiranje in upravljanje potreb po spremembah. } \\
\text { - Učinkovito upravljanje časa in virov. } \\
\text { - Učinkovito sodelovanje z različnimi posamezniki člani tima, skupinami in drugimi } \\
\text { - } \quad \text { Uporganizacijami. } \\
\text { - Ocena uspešnosti sebe in sodelavcev. }\end{array}$ \\
\hline 9 & Prilagodljivost spremembam & $\begin{array}{l}\text { - Prepoznavanje sprememb v okolju. } \\
\text { - Ugotoviti naravo sprememb. } \\
\text { - Presoditi, kako te spremembe vplivajo na delo in organizacijske strategije v smislu } \\
\text { tveganj in priložnosti. } \\
\text { - Prepoznavanje in analiza različnih vidikov dane situacije, ki so pomembni za doseganje } \\
\text { specifičnih ciljev, in ocena, do kakšne mere je treba te vidike prilagoditi zaradi } \\
\text { sprememb. } \\
\text { - Oceniti potrebne napore za vpeljavo sprememb. }\end{array}$ \\
\hline 10 & Voditeljstvo (leadership) & $\begin{array}{l}\text { - Pojasniti, kako voditeljstvo deluje in je razumlieno v organizacijah. } \\
\text { - } \quad \text { Prepoznavanje lastnih prednosti in potrebe postati vodja (leader). } \\
\text { - } \quad \text { Opisati pomembne lastnosti in obnašanje učinkovitih vodij. } \\
\text { - } \quad \text { činkovito delo in različna opravila za uporabo situacijskih tehnik leadershipa. }\end{array}$ \\
\hline 12 & Usmerjenost $\mathrm{k}$ rezultatom & $\begin{array}{l}\text { - Uporaba orodij in tehnik, da projekti ostanejo usmerjeni k ciljem. } \\
\text { - } \quad \text { Zagon aktivnosti za optimizacijo virov, potrebnih za doseganje rezultatov. } \\
\text { - } \quad \text { Vzdrževanje potrebnih procesov, ki so usmerjeni v kakovost rezultatov in prispevajo k } \\
\text { izboljšavam procesov. } \\
\text { - } \quad \text { Vzdrževanje timskega dela in vzpostavljanje timov (teambuilding) predvsem v delu, ki } \\
\text { - } \quad \text { Rahteva medsebojno vzajemno odvisnost. } \\
\text { - } \quad \text { Pospeševanje sprejemanja odločitev z minimiziranjem tveganj. }\end{array}$ \\
\hline 13 & Stalne izboljšave & $\begin{array}{l}\text { - } \quad \text { Postavljanje merljivih ciljev. } \\
\text { - } \quad \text { Uporaba kakovostnih variacii vzrokov. } \\
\text { - } \quad \text { Določitev časovnih okvirov, nalog, odgovornosti in virov, potrebnih za doseganje } \\
\text { izboljšav. } \\
\text { - } \\
\text { Merjenje rezultatov izboljšav in primerjava s pričakovanimi indeksi izboljšav. }\end{array}$ \\
\hline
\end{tabular}




\begin{tabular}{|c|c|c|}
\hline & Mehka veščina & Učni dosežki \\
\hline 14 & Pogajanja & $\begin{array}{l}\text { - } \quad \text { Priprava pogajalskega načrta in strategije. } \\
\text { - } \quad \text { Vzpostavlianje pozitivnega in konstruktivnega vzdušja za pogajalsko mizo. } \\
\text { - } \quad \text { Odprtost, da spremeniš svoje stališče. }\end{array}$ \\
\hline 16 & $\begin{array}{l}\text { Odpornost proti stresnim situ- } \\
\text { acijam }\end{array}$ & $\begin{array}{l}\text { - Identifikacija pozitivnih in negativnih plati stresa in spoznanje, da je stres reakcija na } \\
\text { - } \quad \text { Prepitivne in negativne izkušnje ter tako del živlienja. } \\
\text { - } \quad \text { Pozicionirati aktivnosti, ki povečujejo stres. } \\
\text { - } \quad \text { Uporabiti tehnike, ki pomagajo upravljati stres. } \\
\text { - } \quad \text { Narediti načrt za zmanjševanje in upravljanje stresa. }\end{array}$ \\
\hline 18 & Življenjsko ravnotežje & $\begin{array}{l}\text { - Identifikacija težav zaradi neučinkovitega iskanja ravnotežja med zasebnim in } \\
\text { profesionalnim življenjem. } \\
\text { - Vzpostaviti uravnoteženo razdelitev časa med različne osebno pomembne vidike. } \\
\text { - Izboljšati upravljanje delovnih obremenitev s tehnikami in pristopi za upravljanje časa, } \\
\text { interakcijo s sodelavci in medsebojnim razumevanjem. }\end{array}$ \\
\hline 19 & Upravljanje konfliktov & $\begin{array}{l}\text { - Izražanje in razumevanje notranjih in medosebnih konfliktov in povezanih pojavov, na } \\
\text { primer frustracije ter notranjega in medosebnega stresa. } \\
\text { - Zavedanje povezave med osebnostjo in slogom upravljanja konfliktov. } \\
\text { - Uporaba medkulturnih virov za krepitev sodelovanja in boljše upravljanje konfliktov v } \\
\text { posebnem kulturnem kontekstu. } \\
\text { - Uporaba obstoječih in novopridobljenih spretnosti, na primer aktivnega poslušanja, } \\
\text { napredne empatične refleksije, konfrontacije in povzemanja, za upravljanje konfliktov } \\
\text { in njihovo razreševanje. }\end{array}$ \\
\hline 20 & Kulturna prilagodljivost & $\begin{array}{l}\text { - } \text { Razumevanje bogastva kulturnih razlik. } \\
\text { - } \quad \text { Sposobnost, fleksibilnost in prilagajanje novim okoljem. } \\
\text { - } \quad \text { Opis odnosa med kulturo in komunikativnostjo. } \\
\text { - Uporaba »občutljivosti« v kulturnih razlikah. }\end{array}$ \\
\hline 21 & Mreža stikov & $\begin{array}{l}\text { - Razumeti pomen mreženja in s tem povezanih veščin. } \\
\text { - Uporaba ključnih veščin za ustvarjanje razmerij. } \\
\text { - Utrjevanje mreže z obstoječimi in potencialnimi člani. } \\
\text { - Učinkovito upravljanje in administriranje mreže. } \\
\text { - } \quad \text { Motivirano in ciljno usmerjeno obnašanje. }\end{array}$ \\
\hline 22 & $\begin{array}{l}\text { Veščine raziskovanja in upravl- } \\
\text { janja informacij }\end{array}$ & $\begin{array}{l}\text { - Učinkovito iskanje potrebnih informacij. } \\
\text { - } \text { Ovrednotenje informacij, ki jih najdemo na internetu. } \\
\text { - } \quad \text { Razumevanje ekonomskih, pravnih in družbenih vidikov uporabe informacij in dostop } \\
\text { - } \quad \text { Po informacij, ki je legalen in etičen. } \\
\text { - } \quad \text { Organizacija, upravljanje in predstavitev informacij. } \\
\text { - Učinkovita uporaba informacij za doseganje ciljev. }\end{array}$ \\
\hline
\end{tabular}

Vir: prilagojeno po Haselbergerin drugi (2012: 85-89) 
kontekstu se zdi razprava o mehkih veščinah v visokošolskih programih ne samo relevantna, ampak eden od možnih odgovorov in usmeritev za vsebinsko in metodološko prenovo visokošolskih programov.

Nabor mehkih veščin, kot je opravljen v pričujoči študiji, lahko služi kot dobro izhodišče za razmislek, kako te veščine vključevati v posamezne študijske programe. Pri tem je seveda treba razmisliti predvsem o metodologiji proučevanja in odgovoriti na dilemo, ali naj se mehke veščine vključujejo na ravni posameznega študijskega programa ali kot zunajprogramske aktivnosti. Tudi pri odločitvi o vključitvi na ravni programa ostaja vprašanje, ali je mehke veščine smiselno podajati kot integralne dele posameznih učnih enot (modulov, predmetov) ali kot samostojne obvezne ali izbirne vsebine posameznih programov.

Študija postavlja temelje za razmislek o vključevanju opredeljenih mehkih veščin, vendar se ne ukvarja z vprašanjem metodologije. Verjetno bo šlo predvsem za obliko eksperimentalnega razvoja, katerega osrednji nosilec bo učitelj, ki bo ob vstopu $\mathrm{v}$ ta proces najprej moral preseči okvir razmišljanja in načinov poučevanja, temelječih na tradicionalističnem evropskem pristopu k visokošolskemu izobraževanju.

\section{LITERATURA IN VIRI}

Aksal, F., Altinay, G., Zehra, A., Isman, A. (2008). $»$ A comprehensive look into the learner's transferable skills related to constructivist apporach." World Applied Sciences Journal, 4 (4): 558-567.

Barrie, S. C. (2007). »A conceptual framework for the teaching and learning of generic graduate attributes «. Studies in Higher Education, 32(4): 439-458. R. (2006). »Promotive activities in face-to-face and technology enhanced learning environments. The Person-centered Journal, 13:1-2.

Chur, D. (2004). »Schlüsselkompetenzen Herausforderung für dir (Aus-)Bildungsqualität an Hochschulen«. V: Meyer-Guckel, V., Sonnabend, M. (ur.), Stifterverband für den Deutsche Wissenschaft, Schlüsselkompetenzen un Beschäftigungfähigkeit. Konzepte für die Vermittlung über fachlicher Qualifikationen an Hochschulen, Essen.

Duncan, G., Dunifon, R. (1998). »Soft skills and long-run labour market success «. Research in Labour Economics. Dostopno na: http://ssrn.com/ abstract $=112431$.

Dunlap, J. C. (2005). »Problem-based learning and self-efficacy: How a capstone course prepares students for a profession«. Educational Technology Research and Development, 53(1): 65-83.

Gee, J. P. (2008). Game-like learning - an example of situated learning and implications for opportunity to learn. Dostopno na: http://www.jamespaulgee.com/node/29 (pridobljeno 15. 5. 2011).

Gruba, P., Søundergaard, H. (2001). »A constructivistapproach to communicationskillsinstruction in computerscience «. Computer Science Education 11 (3): 203-219.

Harvey, L. (1999). New Realities - The Relationship between Higher Education and Employment. Dostopno na: http://www.qualityresearchinternational.com/ese/relatedpubs/New_Realties. pdf(pridobljeno 17. 5. 2011).

Haselberger, D., Oberheumer, P., Perez, E., Cinque, M., Capasso, F. (2012). MODES - Mediating Soft Skills at Higher Education Institutions. Guidelines for the design of learnin gsituations supporting soft skills achievement. Dostopno na: http:// www.modesproject.eu/images/documents/handbook20120915_final-1.pdf

Knight, P., Page, A. (2007). The assesment of »wicked « competences. Report to the practice-based Professional Learning centre. Dostopno na: http://www.open.ac.uk/cetl-workspace/cetlcontent/documents/460d21bd645f8.pdf (pridobljeno 31. 1. 2011).

Ko, E. (2010).Can Teamwork Skills be Taught and 
Assessed?Dostopno na: http://celt.ust.hk/seminar/ edmundko/20100331_EdmundKo.pdf (pridobljeno 31. 1. 2010).

Kohler, J. (2004). »Schlüsselkompetenzen und »employability« im Bologna-Prozess«. V: Meyer-Guckel, V., Sonnabend, M. (ur.), Stifterverband für den Deutsche Wissenschaft, Schlüsselkompetenzen un Beschäftigungfähigkeit. Konzepte für die Vermittlung überfachlicher Qualifikationen an Hochschulen, Essen.

Lave, J.,Wenger, E. (2000). Situatedlearning Legitimate Periperal Participation. Cambridge: Cambridge UniversityPress.

Yorke, M., Longden B. (2008). The First YearExperience in theHigherEducation in UK. FinalReport. London: Thehighereducationacademy.

McLellan, H. (1985). Situated learning perspectives. . Englewood Cliffs: Educational technology publications.

Motschnig-Pitrik, R., Rohlíková, L. (2013). »Constructivist and Person-Centered Learning in Higher Education - Using Indicators and Case Examples for Comparing Good Practice«. Computer and Information Science, 278(1): 44-57.

Mothschnig-Pitrik, R., Holzinger, A. (2002). Student-centred teaching meets new media concept and case study. Educational Technology \& Society, 5(4): 160-172.

Mothschnig, R. (2010). A person-centered facilitator's reflections on constructivist and person-centered learning. Kralove: Conference on eLearning.

Murphy, E. (2003). »Moving From Theory to Practice in the Design of Web-Based Learning From the Perspective of Constructivism «. Journal of Interractive Online Learning, 1(4): 67-85.

Rogers, C. R. (1983). Freedom to learn for the 80's. New York: MacMillanPublishingCompany.

Rogers, C. R. (2005). Client Centered therapy. London: Constable.

Schmidt, S. J. (1987). »Der radikale Konstruktivismus: ein Neues Paradigma in interdisziplinärenDiskurs«. V: Schmidt, S. J. (ur.): Der Diskurs des radikalen Konstruktivismus, Frankfurt am Main.
Shakespeare, P., Keleher, P., Moxham, L. (2007). »Softskills, hardskills, and practise identity«. V: Soft skills for better employability, Icfai.

Von Glasersfeld, E. (1997). Radikaler Konstruktivismus. Frankfurt am Main: SuhrkampVrlag.

Vukasovic, M. (2006). »Deconstruction and reconstructing Employability«. V: Fromet, E., in drugi (ur.), EUA Bologna Handbook - Making Bologna Work, Berlin.

Welbers, U. (2004). »Schlüsselqualifikationen - Strategien zu ihrer Vermittlung am Germanistischen Seminar der Universität Düseldorf «. V: Meyer-Guckel, V., Sonnabend, M. (ur.): Stifterverband für den Deutscha Wissenschaft, Schlüsselkompetenzen un Beschäftigungfähigkeit. Konzepte für die Vermittlung überfachlicher Qualifikationen an Hochschulen, Essen.

Wenger, E. (2006). Communities of Practise - A brief introduction. Dostopno na:: http://www. ewenger.com/theory/index.htm(15.5.2011).

Yuan, Y., McKelvey, B. (2004). Situated learning theory: Adding rate and complexity Effects via Kauffman's NK model. Nonlinear Dynamics, Psychology and Life Sciences, 8(1): 65-102. 